\title{
Autoconceito, hábitos de estudo, procrastinação e rendimento escolar: que relação?
}

\section{Self-concept, study habits, procrastination and school achievement: which} relation?

\author{
Maria da Graça Amaro Bidarra, M. Piedade Vaz-Rebelo, Carlos Folgado Barreira, Valentim Rodrigues Alferes, Ana \\ Catarina Pereira \\ Universidade de Coimbra
}

\begin{abstract}
Resumo
$\mathrm{Na}$ presente investigação procura-se testar o valor preditivo das variáveis autoconceito, hábitos de estudo e procrastinação na explicação do rendimento escolar, junto de alunos portugueses que frequentam o $2^{\circ}$ ciclo do ensino básico, concluindo-se que, de acordo com as medidas adotadas, estes três preditores explicam $70 \%$ da variabilidade dos resultados escolares, sendo os hábitos de estudo o preditor mais relevante.

Palavras chave: autoconceito, hábitos de estudo, procrastinação, rendimento escolar
\end{abstract}

\begin{abstract}
In the present research, the predictive value of selfconcept, study habits and procrastination in the explanation of school performance was tested. The participants were Portuguese students who attend the 2nd cycle of elementary education and it was concluded that, according to the measures adopted, the three predictors explain $70 \%$ of the variability of the school results, being the study habits the more relevant predictor.

Keywords: self-concept, study habits, procrastination, school performance
\end{abstract}

Os hábitos de estudo, bem como a procrastinação no estudo e o autoconceito têm vindo a ser estudados, tanto isoladamente como em relação com outras variáveis, designadamente em relação com o rendimento escolar. Com efeito, más notas, atraso nos trabalhos e estudo, abandono ou desistência e incumprimento de tarefas são apontados como resultados da procrastinação (Costa, 2007) e a atitude negativa, a desmotivação e o tempo que dedicam ao estudo são características de alunos sem hábitos regulares de estudo (Carvalho, 2011; Rosário, Almeida, \& Oliveira, 2000). Por sua vez, a relação entre o autoconceito e o rendimento académico tem sido igualmente destacada (Campira, Araújo \& Almeida., 2014; Lourenço \& Paiva, 2011; Veiga, 2006).

$\mathrm{Na}$ presente investigação analisam-se as relações de interdependência entre estas variáveis, procurando testar o seu valor preditivo na explicação do rendimento escolar.

\section{Método}

\section{Participantes}

Participaram no estudo 19 alunos de uma escola básica pertencente a um agrupamento de escolas da região centro de Portugal Continental, que frequentavam uma turma do $6^{\circ}$ ano, do $2^{\circ}$ ciclo do ensino básico, sendo que 11 eram do sexo feminino e 8 eram do sexo masculino.

\section{Medidas}

Utilizaram-se as seguintes medidas: Questionário de Procrastinação no Estudo (QPE) (Costa, 2007), Inventário de Estratégias de Estudo (IEE) (Leal \& Almeida, 1993, adaptado por Sampaio \& Carvalho, 2011), e Piers-Harris Children's Self-Concept Scale (PHCSCS-2) (Piers \& Herzberg, 2002, adaptado por Veiga, 2006), tomando como indicador do rendimento escolar, a média das classificações nas disciplinas de Português, Matemática, História e Geografia de Portugal, Ciências da Natureza e Inglês, do $3^{\circ}$ período, e das provas finais do ensino básico, do ano letivo de 2014/2015.

\section{Resultados}

Considerando o valor das correlações simples entre as variáveis em estudo e o rendimento escolar, destaca-se a correlação significativa entre os hábitos de estudo e o rendimento escolar (.77) e concomitantemente uma correlação negativa entre a procrastinação no estudo e o rendimento escolar (- .43), sendo mais baixa a correlação entre o autoconceito e o rendimento escolar (.13). De acordo com a análise de regressão múltipla, tomando como critério o rendimento escolar e como preditores o autoconceito (PHCSCS), os hábitos de estudo (IEE) e a procrastinação no estudo (QPE), os dados revelam que se considerarmos os três preditores simultaneamente, o coeficiente de correlação múltipla é de .84, o que corresponde a um coeficiente de determinação múltipla de .70 (cf. Tabela 1). 
Tabela 1

Regressão do rendimento escolar nas estratégias de estudo (IEE), na procrastinação (QPE) e no aut

\begin{tabular}{|c|c|c|c|c|c|c|}
\hline \multicolumn{5}{|c|}{ Regressão Múltipla* } & \multicolumn{2}{|c|}{ Correlações } \\
\hline & B & $\beta$ & tobs & $p$ & $r$ & $s r^{2}$ \\
\hline Constante & -6.62 & 一 & -2.60 & .020 & 一 & - \\
\hline IEE & .09 & 1.22 & 5.08 & .000 & .77 & .52 \\
\hline QPE & .07 & .51 & 2.17 & .046 & -.43 & .10 \\
\hline PHCSCS & -.02 & -.12 & -.80 & .438 & .13 & .01 \\
\hline
\end{tabular}

Os três preditores conjuntamente explicam $70 \%$ da variabilidade dos resultados escolares. Se atendermos aos contributos únicos, dados pelas correlações semi-parciais ao quadrado, o contributo específico dos hábitos de estudo (IEE) é de .52 , o da procrastinação no estudo (QPE) é de .10, sendo o do autoconceito de .01. Destacam-se, pois, os hábitos de estudo como o preditor mais relevante.

\section{Discussão}

Os dados obtidos vão ao encontro de outros estudos, nomeadamente de Costa (2007), onde se verificou que a procrastinação no estudo aumentava à medida que as notas de Português e Matemática diminuíam. Considerando que a autorregulação da aprendizagem está relacionada de forma positiva com o rendimento académico, este estudo revelou ainda que a alunos que autorregulam a sua aprendizagem procrastinam menos. Uma das explicações apontadas para esta situação é o facto de os alunos recorrem à procrastinação como uma desculpa para a sua incapacidade de autorregulação e consequentemente insucesso escolar (Costa, 2007).

Concomitantemente, constata-se uma tendência para o aumento dos hábitos de estudo em simultâneo com o aumento do rendimento escolar, concluindo-se que os alunos que recorrem a estratégias de estudo são aqueles que apresentam melhores resultados escolares.

Para além de convergir com outros estudos, este resultado pode ser justificado pelo facto dos alunos com mais hábitos de estudo desenvolverem competências como a procura de informação complementar, organização e retenção da informação, adequação do ambiente de estudo, revisão das matérias e sistematização das mesmas, "que influenciam os resultados escolares dos alunos" (Carvalho, 2012, p. 85). A aquisição de hábitos de estudo corresponde a uma autorregulação do mesmo, que por sua vez se reflete em melhores resultados escolares (Carvalho, 2012), constituindo assim "um fator preponderante no desempenho e nos resultados escolares" (Almeida et al, 2005, citado por Carvalho, 2012, p.83). Também Rosário, Almeida e Oliveira (2000), através da sua investigação, afirmam que o sucesso escolar está inevitavelmente relacionado com as estratégias de estudo e autorregulação da aprendizagem, alegando ainda que a ausência de hábitos e estratégias de estudo nos alunos advém do fraco investimento das escolas nesse sentido.
Constata-se ainda, uma correlação positiva entre o autoconceito e o rendimento escolar, significando assim que os alunos que apresentam uma melhor perceção sobre si mesmos tendem a obter melhores resultados escolares. Os alunos que reconhecem o seu desempenho, que se percecionam e avaliam tendem a obter melhores resultados escolares (Miranda \& Almeida, 2006, citado por Campira, Araújo \& Almeida, 2014). Também Lourenço e Paiva (2011) afirmam que "as perceções negativas dos sujeitos acerca deles próprios constituem um fator-chave do insucesso escolar" (p.400), sendo que essa perceção negativa pode resultar da experimentação constante do fracasso escolar e repreensões (Veiga, 2001, citado por Lourenço \& Paiva, 2011).

Considerando estes resultados e respetivas análises, conclui-se que as três variáveis, procrastinação, hábitos de estudo e autoconceito, corresponderem a cerca de $70 \%$ da explicação para o rendimento escolar.

\section{Referências}

Campira, F., Araújo, A., \& Almeida, L. (2014). Autoconceito e rendimento escolar em adolescentes moçambicanos. I Seminário Internacional sobre Cognição, Aprendizagem e Rendimento, 78-87. Braga: Universidade do Minho. Instituto de Educação. Centro de Investigação em Educação. .

Carvalho, A. (2011). Hábitos de estudo e a sua influência no rendimento escolar. Dissertação de Mestrado (não publicada) em Psicologia Clínica e da Saúde apresentada à Faculdade de Ciências Sociais e Humanas: Universidade Fernando Pessoa.

Costa, M. (2007). Procrastinação, autorregulação e género. Tese de Mestrado em Psicologia (na área de especialização em Psicologia Escolar) apresentada ao Instituto de Educação e Psicologia: Universidade do Minho.

Lourenço, A., \& Paiva, M. (2011). Rendimento académico: Influência do autoconceito e do ambiente de sala de aula. Psicologia: Teoria e Pesquisa, 27 (4), 393-402.

Rosário, P., Almeida, L., \& Oliveira, A. (2000). Estratégias de auto-regulação da aprendizagem, tempo de estudo e rendimento escolar : Uma investigação no ensino secundário. Psicologia : Teoria, Investigação e Prática, 2, 197-211

Sampaio, R., Polydoro, S., \& Rosário, P. (2012). Autorregulação da aprendizagem e a procrastinação acadêmica em estudantes universitários. Cadernos de Educação ,42, 119-142.

Veiga, F. (junho de 2006). Uma nova versão da escala de autoconceito - Piers-Harris Children's self-Concept Scale (PHCSCS). Psicologia e Educação , 5 (1), 39-48.

Silva, A., \& Sá, I. (1997). Saber estudar e estudar para saber ( $2^{\mathrm{a}}$ ed.). Porto: Porto Editora. 